\title{
Comparative side-effects of adapalene and benzoyl peroxide combination gel with Adapalene monotherapy and Benzoylperoxide monotherapy in the treatment of Acne vulgaris.
} Islam $\mathrm{KA}^{1}$, Akhtar $\mathrm{N}^{2}$, Shahidullah $\mathrm{M}^{3}$, Khondker $\mathrm{L}^{4}$, Khan $\mathrm{MSI}^{5}$

\begin{abstract}
A controlled clinical trial was conducted in the department of Dermatology and Venereology, Bangabandhu Sheikh Mujib Medical University (BSMMU), Dhaka, Bangladesh to compare the side-effects of adapalene and benzoyl peroxide combination gel with adapalene monotherapy and benzoyl peroxide monotherapy in the treatment of acne vulgaris. The study conducted in sixty patients. Group A (case) 20 patients were treated with adapalene and benzoyl peroxide combination gel, group B (control) 20 patients were treated with topical adapalene and group C (control) 20 patients were treated with topical benzoyl peroxide. The side effects experienced by patients of different groups in their first follow up were noticed. In group A - erythema, scaling, dryness, burning and pruritus were present in $45 \%, 10 \%, 35 \%, 40 \%$ and $10 \%$ of patients and in group B, 35\%, 25\%, 30\%, 35\% and 15\% respectively. However in group C dryness and pruritus were absent in all the patients and the erythema, scaling and burning were $30 \%, 25 \%$ and $25 \%$ respectively. In $5^{\text {th }}$ follow-up visit, in group A- erythema, scaling, dryness and pruritus were present in $15 \%, 5 \%, 15 \%$, and $5 \%$ of patients respectively and burning was absent in group $\mathrm{A}$. In group B erythema, scaling, dryness, and pruritus were $15 \%, 5 \%, 5 \%$ and $5 \%$ and burning was absent in group B. However in group C scaling, burning, dryness and pruritus were absent in all the patients. Erythema was present in $10 \%$ cases in $5^{\text {th }}$ follow-up visit. It was evidenced in the present study that the overall adverse effect is slightly higher with the adapalene- benzoyl peroxide combination therapy in relation to the adapalene and benzoyl peroxide (BPO) monotherapies in the treatment of acne vulgaris.
\end{abstract}

Key words: Adapalene, Benzoyl peroxide, Acne Vulgaris.

\section{Introduction}

Acne vulgaris is a chronic inflammatory disease of the pilosebaceous follicles that occurs primarily in adolescents. Most cases of acne consist of comedones, papules, pustules, and nodules. Although the course of acne may be self-limiting, the sequelae can be life long, with pitted or hypertrophic scar formation. ${ }^{1}$ Lesions of acne vulgaris can be divided into non-inflammatory (open and closed comedones) and inflammatory (papules, pustules and nodules). ${ }^{2}$ Overgrowth of the bacteria can lead to precipitation of an innate immune response and in some cases, rupture of follicular wall may occur initiating a host inflammatory reaction leading to inflammatory acne.,4 Accordingly, antimicrobial agents have been a mainstay of acne therapy targeting P. acne colonies. ${ }^{5}$ In acne, the host response to $P$. acnes can result in the production of proinflammatory
1. *Dr. Kismat Ara Islam, Assistant Professor, Department of Dermatology and Venereology. Shaheed Monsur Ali Medical College and Hospital, Uttara, Dhaka.

2. Dr. Nargis Akhtar,

Associate Professor, Department of Dermatology and Venereology.Bangabandhu Sheikh Mujib Medical University (BSMMU)., Shahbag, Dhaka, Bangladesh.

3. Professor (Dr). Md Shahidullah, Head, Dept of Dermatology and Venereology, Shaheed Monsur Ali Medical College and Hospital, Dhaka.

4. Dr. Lubna Khondker, Assistant Professor of Dermatology and Venereology, Bangabandhu Sheikh Mujib Medical University, Shahbag, Dhaka.

5. Lt Col (Dr). Md Shirajul Islam Khan, Graded Specialist in Dermatology and Venereology, Combined Military Hospital, Dhaka.

*Address of correspondence:

E-mail: lubnaderma@gmail.com Mobile: 008801552370429 
cytokines, such as tumor necrosis factor- $\alpha$ (TNF- $\alpha$ ), interleukin (IL)-1 $\alpha$, and IL-8 and contribute to the clinical manifestations of the disease. $^{3,4}$

Topical treatments are generally recommended for mild to moderate acne. The most frequently prescribed products are retinoids and benzoyl peroxide. ${ }^{6}$ Adapalene is the $3^{\text {rd }}$ generation retinoid. The chemical name of adapalene is 6-\{3-(1-adantyl)-4methoxyphenyl\} -2-napthoic acid. These agents target comedogenesis by normalizing desquamation of the follicular epithelium, preventing the formation of new microcomedo precursor lesions, thus minimizing the formation of both inflammatory acne lesions and comedones. ${ }^{7}$ During the first month of therapy adverse effects like erythema, scaling, burning sensation, stinging sensation, dryness and irritation, pruritus, acne flares etc are most commonly encountered. ${ }^{8}$ Benzoyl peroxide is frequently used as a first-line therapy for mild to moderate acne. Benzoyl peroxide acts through oxidation and formation of free radicals causing a reduction of $P$. acnes. This mechanism helps to prevent an induction of resistance in P. acnes often observed during long term acne treatment with antibiotics. However, benzoyl peroxide can cause skin irritation and drying ${ }^{9}$ and in $1 \%$ of patients, contact allergy may develop. ${ }^{10}$ Redness, desquamation and burning of treated skin are the dose dependent major symptoms of therapy. ${ }^{11}$ The present study was therefore aimed to explore the side-effects of adapalene $0.1 \%$ and benzoyl peroxide (BPO) $2.5 \%$ combination gel compared to adapalene $0.1 \%$ monotherapy and benzoyl peroxide (BPO) $2.5 \%$ monotherapy in the treatment of acne.

\section{Methods}

A controlled clinical trial was conducted in the department of Dermatology and Venereology at Bangabandhu Sheikh Mujib Medical University, Dhaka during the period of September 2010 to Feburay 2011. The study encompassed enrolment of a total of 60 patients. Purposive type sampling technique was followed in this study and data were collected in the structured questionnaire.
Group A (case) 20 patients were treated with adapalene and benzoyl peroxide combination gel, group B (control) 20 patients were treated with topical adapalene and group C (control) 20 patients were treated with topical benzoyl peroxide. Inclusion criteria were: patients clinically diagnosed as acne vulgaris, having age $\geq 12$ years and of both sexes, patients with non-inflammatory (comedones) lesions and inflammatory (papules, pustules) lesions on the face and female who were not on oral contraceptive pill. Exclusion criteria were: patients suffering from nodulo-cystic acne, pregnant women and lactating mother, persons having hypersensitivity to adapalene and benzoyl peroxide and patients with other dermatologic conditions interfering with the treatment of acne vulgaris

\section{Ethical Issues}

All patients were given an explanation of the study including the potential risks and obtainable benefits. Patients were included in the trial after taking their informed consent. They were explained about the right to refuse or accept to participate in the study. All patients were ensured that all data obtained during study period will be kept confidential.

\section{Procedure of data collection}

A total number of sixty patients were primarily selected and they were randomized using computer-generated codes into three groups (group-A and group-B \& group-C). Complete history, general physical examination and dermatological examinations were done for all enrolled patients. For women of reproductive age reproductive history, menstrual history, lactation and pregnancy plan were carefully judged. History and physical findings were recorded in a structured questionnaire. Finally those patients, who matched the inclusion and exclusion criteria according to history, physical examination and freely gave their informed consent, were selected for the study. Patients were divided into three groups. The first group was given adapalene and benzoyl peroxide combination gel once daily in the evening for 12 week. The second and third groups were given adapalene cream and benzoyl peroxide cream respectively. Patients were clinically assessed at baseline 
and at week 1, 2, 4, 8 and 12. The patients included in this study were prescribed the generic formulation of adapalene and benzoyl peroxide combination gel, topical adapalene and topical benzoyl peroxide, which are available in the market.

\section{Data processing and analysis}

Data analysis was performed by Statistical Package for Social Science (SPSS), version12. Data were edited, coded and entered into the computer. Statistical analyses were done and level of significance was measured by using appropriate procedures like chi square test $\left(x^{2}\right)$, relative risk (RR) measurement, t-test, proportion (d) test, ANOVA tests and others where applicable.

\section{Results}

Total 60 patients were enrolled. Group A (case) 20 patients were treated with adapalene and benzoyl peroxide combination gel, Group B (control) 20 patients were treated with topical adapalene and Group C (control) 20 patients were treated with topical benzoyl peroxide. Table 1 reveals the mean age of group $A$, group $B$ and group $C$ patients were $21.50 \pm 3.32,21.55 \pm 4.12$ and $22.25 \pm$ 4.67 respectively. There was no significant difference of age between the groups. In group $A$ and $B \quad 40 \%$ of the patient were male and $60 \%$ were female patient. In group C $45 \%$ were male patient and $55 \%$ were female patient.

The side effects experienced by patients of different groups in their first follow up were shown in figure I. In group A - erythema, scaling, dryness, burning and pruritus were present in $45 \%, 10 \%, 35 \%, 40 \%$ and $10 \%$ of patients respectively. In group B - erythema, scaling, dryness, burning and pruritus were $35 \%, 25 \%, 30 \%, 35 \%$ and $15 \%$. However in group C - dryness and pruritus were absent in all the patients and the erythema, scaling and burning were $30 \%, 25 \%$ and $25 \%$ respectively. Table 2 represents side effects of the 5th follow-up visit. In group Aerythema, scaling, dryness and pruritus were present in $15 \%, 5 \%, 15 \%$, and $5 \%$ of patients respectively, and burning was absent in group A. In group B erythema, scaling, dryness, and pruritus were $15 \%, 5 \%, 5 \%$ and $5 \%$ and burning was absent in group B. However in group C scaling, burning, dryness and pruritus were absent in all the patients and the erythema were present in $10 \%$ cases in $5^{\text {th }}$ follow-up visit.

Table 1: Distribution of age and sex of the patients by groups.

\begin{tabular}{|c|c|c|c|c|}
\hline \multirow{2}{*}{$\begin{array}{l}\text { Age (in } \\
\text { years) }\end{array}$} & \multicolumn{3}{|c|}{ Groups } & \multirow[b]{2}{*}{ * p value } \\
\hline & $\begin{array}{l}\text { Group A } \\
(n=20)\end{array}$ & $\begin{array}{l}\text { Group B } \\
(n=20)\end{array}$ & $\begin{array}{l}\text { Group C } \\
(n=20)\end{array}$ & \\
\hline \begin{tabular}{|l|}
$15-19$ \\
$20-24$ \\
$25-29$ \\
Mean \pm \\
SD
\end{tabular} & $\begin{array}{l}7(35 \%) \\
9(45 \%) \\
4(20 \%) \\
21.50 \pm 3.32\end{array}$ & \begin{tabular}{|l|}
$8(40 \%)$ \\
$6(30 \%)$ \\
$6(30 \%)$ \\
$21.55 \pm 4.12$
\end{tabular} & $\begin{array}{l}7(35 \%) \\
6(30 \%) \\
7(35 \%) \\
22.25 \pm 4.67\end{array}$ & .810 \\
\hline Sex & $\begin{array}{l}\text { Group A } \\
(n=20)\end{array}$ & $\begin{array}{l}\text { Group B } \\
(n=20)\end{array}$ & $\begin{array}{l}\text { Group C } \\
(n=20)\end{array}$ & \\
\hline \begin{tabular}{|l|} 
Male \\
Female
\end{tabular} & $\begin{array}{l}8(40 \%) \\
12(60 \%)\end{array}$ & $\begin{array}{l}8(40 \%) \\
12(60 \%)\end{array}$ & \begin{tabular}{|l|}
$9(45 \%)$ \\
$11(55 \%)$
\end{tabular} & \begin{tabular}{|l}
.937 \\
\end{tabular} \\
\hline
\end{tabular}

${ }^{*}$ ANOVA test done to measure significance

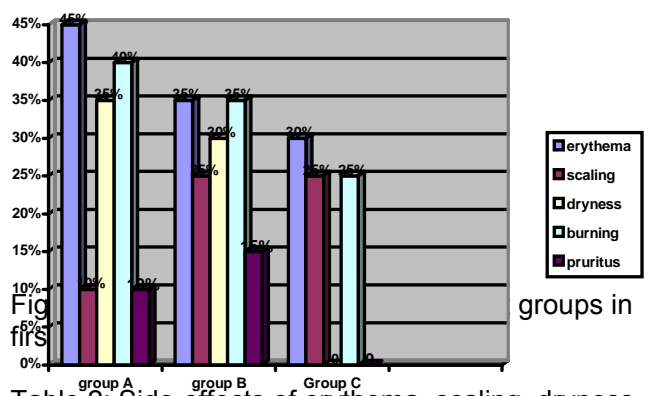

Table 2: Side-effects of erythema, scaling, dryness, burning and pruritus in 5th follow up

\begin{tabular}{|l|l|l|l|}
\hline \multirow{2}{*}{$\begin{array}{l}\text { Side } \\
\text { effects }\end{array}$} & \multicolumn{3}{|c|}{ Different Groups } \\
\cline { 2 - 4 } & $\begin{array}{l}\text { Group A } \\
\text { (n =20) }\end{array}$ & $\begin{array}{l}\text { Group B } \\
\text { (n=20) }\end{array}$ & $\begin{array}{l}\text { Group C } \\
\text { (n =20) }\end{array}$ \\
\hline Erythema & $3(15 \%)$ & $3(15 \%)$ & $2(10 \%)$ \\
Scaling & $1(5 \%)$ & $1(5 \%)$ & $0(0 \%)$ \\
Dryness & $3(15 \%)$ & $1(5 \%)$ & $0(0 \%)$ \\
Burning & $0(0 \%)$ & $0(0 \%)$ & $0(0 \%)$ \\
Pruritus & $1(5 \%)$ & $1(5 \%)$ & $0(0 \%)$ \\
\hline
\end{tabular}

\section{Discussion}

A total of sixty patients were primarily selected based on inclusion criteria of the study and randomly assigned to one of the three groups (group A, group B and group C). Acne vulgaris is a common skin disorder that is experienced by most people at some stage during their lifetime. It accounts for approximately $25 \%$ of patient visits in private 
dermatology practice in the U.S.A. ${ }^{12}$. Acne affects $95 \%$ of the 16 years old boys and $83 \%$ of 16 years old girls to some degree. The incidence and the severity of acne peak at $40 \%$ in 14 to 17 years old girls and at $35 \%$ in boys aged 16 to 19 years. Despite its spontaneous regression in most patients, acne persists in $10 \%$ of those patients over the age of 25 years $^{13}$. In the present study thirty five percent of patients of adapaleneBPO and BPO were from the age group of 15 to 19 years and $40 \%$ of adapalene patient belong to the same age group. In adapalene and BPO, $30 \%$ of the patients belong to the age group of 20 to 24 years whereas $45 \%$ patients of adapalene-BPO belong to this age group. Twenty percent patients of adapaleneBPO, $30 \%$ patients of adapalene and $35 \%$ patients of BPO belong to the age group of 25 to 29 years. There was no significant difference of age between different groups in this study ( $p$ value 0.810 ). Number of patients in different age group appeared to be almost similar in this study. It is believed to be no gender difference in acne prevalence, although such difference are often reported and very likely, represent social biases ${ }^{14}$. In this study female patients were outnumbered by male patients due to social and cosmetic reasons.

Overall safety and local cuteneous tolerability observed to be similar in patients treated with adapalene - benzoyl peroxide (BPO) and adapalene. Adverse effects like pruritus and dryness of skin were marked in adapalenebenzoyl peroxide (BPO) and adapalene patients. Whereas these cutaneous manifestations were absent in BPO patient. Erythema, scaling and burning/stinging were observed to be present with similar intensity in adapalene-BPO and in adapalene. Local cutaneous tolerability was good for all treatments at each visit. Majority of patients in all of the groups experienced mild adverse effects. Occurance of adverse effects was slightly higher with the combination therapy relative to the monothrapies.

A randomized, double-blind, parallel group study was conducted in which adapalene $0.1 \%+$ BPO $2.5 \%$ gel, adapalene $0.1 \%$ gel, BPO $2.5 \%$ gel or the gel vehicle used nightly for 12 weeks involved 517 acne patients enrolled in a 2:2:2:1 ratio, respectively. Overall, the safety and tolerability results of
adapalene-BPO were comparable with those of adapalene. Local cutaneous tolerability was good for all treatments, with all mean tolerability scores at each visit and worst post baseline scores for erythema, dryness, scaling, and burning/ stinging less than 1 (mild). A majority of subjects in all of the groups experienced mild or no irritation. Mean tolerability scores, based on erythema, scaling, dryness, and stinging / burning, peaked at the first week and declined thereafter. They concluded that fixed-dose combination of adapalene and BPO provides significantly greater safety for the treatment of acne vulgaris as early as week 1 relative to monotherapies, with a comparable safety profile to adapalene ${ }^{15}$. Earlier studies have shown that adapalene can be added to other therapies without significantly increasing skin irritation $^{12,15}$.

A subsequent larger Phase III double-blind, randomized-controlled trial (RCT) with similar trial design involving 1668 patients randomized into the same 4 treatment arms in a 1:1:1:1 ratio was performed in 2009. Over all, more patient in adapalene-BPO combination experienced local tolerability sign and symptoms compare to monotherapy. However, these were transient and mostly mild to moderate in severity. The most frequent treatment-related adverse event was dry skin, which was higher in the combination and adapalene groups than in the BPO monotherapy and vehicle groups (i.e., $6.0 \%$, $4.3 \%, 1.9 \%$, and $2.2 \%$ respectively). ${ }^{16}$

A trans-Atlantic randomized, double-blind, controlled study was carried in patients 12 years of age and older with moderate facial acne vulgaris rated on the Investigator's Global Assessment (IGA), 20 to 50 inflammatory lesions(IL) and 50 to 100 noninflammatory lesions(NIL) for 12 weeks (1:1:1:1 randomization). The local cutaneous tolerability of adapalene-BPO was comparable with adapalene and BPO was good for all treatments, with all mean tolerability scores at each visit and worst post baseline scores for erythema, dryness, scaling and burning /stinging consistent with mild scores (score of $<1$ ). Adapalene-BPO provides significantly greater and synergistic efficacy in the treatment of acne vulgaris combined with a good safety profile when 
compared to vehicle and the adapalene and BPO monotherapies. ${ }^{17}$

A three weeks, randomized, controlled, investigator-blinded, single-center, bilateral (split-face), dose assessment study was done comparing the cutaneous tolerability of adapalene-BPO fixed dose combination products versus various concentrations of BPO monotherapy applied once daily. Sixty patients were randomized to one of the following treatment groups: adapalene $0.1 \%$ BPO $2.5 \%$ combination products versus 2.5 $\%$ BPO monotherapy ; adapalene 0.1\%-BPO 2.5\% combination products versus $5 \%$ BPO monotherapy; adapalene 0.1\%-BPO $5 \%$ combination products versus $5 \%$ BPO monotherapy ; adapalene 0.1\%-BPO 5\% combination products versus $10 \%$ BPO monotherapy. Assessments included total sum score (TSS ) of irritation signs / symptoms ( erythema, scaling , dryness, pruritus, stinging/burning ). The overall cutaneous tolerability profile of the adapalene 0.1\%-BPO2.5\% combination was better than the combination with BPO $5 \%$ and similar to BPO $2.5 \%$ or $5 \%$ monotherapy. The combination product with BPO $5 \%$ induced significantly more irritation than BPO 5\% $(\mathrm{P}<001)$ or BPO $10 \%$ monotherapy $\mathrm{P}=.001)$. In conclusion, the new fixed-dose adapalene $0.1 \%$-BPO $2.5 \%$ combination gel provided the better overall cutaneous tolerability profile relative to other combination. ${ }^{18}$

\section{Conclusion}

It is evidenced from this study that the overall adverse effect is slightly higher with the adapalene- benzoyl peroxide combination therapy relative to the adapalene and benzoyl peroxide (BPO) monotherapies in the treatment of acne vulgaris. These adverse effects were transient and minor in nature, nopatients had to discontinue the treatment for adverse effects and most of the adverse effects were remitted spontaneously without treatment. The clinicians are advised to take into account the adverse effects of therapies encountered whey they prescribe.

\section{References:}

1. Zaenglein AL, Graber EM, Thiboutot and Strauss JS. Acne. In: Klaus Wolff, Lowell AG,

Stephen IK, Barbara AG, Amy SP, David J. Fitzpatrick's Dermatology in General Medicine.

$7^{\text {th }}$ Ed. New York, USA: The McGraw-Hill Companies; 2008. P690-703.
2. Thiboutot DM. Overview of acne and its treatment Cutis 2008; 81(1 Suppl): 3-7.

3. Jeremy $A H$, Holland $D B$, Roberts SG. Inflammatory events are involved in acne lesion initiation. $J$ Invest Dermatol 2003; 121:20-7.

4. Kim J, Ochoa MT, Krutzik SR. Activation of toll-like receptor 2 in acne triggers inflammatory cytokine response. J Immunol 2002; 169: 1535-41.

5. Burkhart CG, Burkhart CN. Expanding the microcomedone theory and acne therapeutics: Propionibacterium acnes biofilm produces biological glue that holds corneocytes together to form plug. J Am Acad Dermatol. 2007; 57(4):722-724.

6. Riddle CC, Amin K, Schweiger ES. A review of azithromycin for the treatment of acne vulgaris. Cosmetic Dermatology 2007; 20 (5); 299-302.

7. Bergfeld WF. The evolving role of retinoids in the management of cutaneous conditions. Clinician 1998; 16:1-32

8. Griffiths CE, Elder JT, Bernard BA et al. Comparison of CD271 (adapalene) and all-trans retinoic acid in human skin: dissociation of epidermal effects and CRABP-II mRNA expression. J Invest Dermatol 2003; 101:325-8.

9. White GM. Acne therapy. In: James WD, Cockerell CJ, Dzubow LW, Paller AS, Yancey KB. Advances in dermatology. St Louis: Mosby; 1999. p. 29-59.

10. Leyden JJ. Therapy for acne vulgaris. N Engl J Med 2007; 336: 1156-62.

11. Worret WI, Fluhr JW. Acne therapy with topical bezoyl peroxide, antibiotics and azelaic acid. J Ger Soci dermatol 2006; 4:293-300

12. Pariser DM, Westmoreland P, Morris $A$ et al. Longterm safety and efficacy of a unique fixed-dose combination gel of adapalene $0.1 \%$ and benzoyl peroxide $2.5 \%$ for the treatment of acne vulgaris. $\mathrm{J}$ Drugs Dermatol 2007; 6:899-905 1.

13. Ebling FJG, Cunliffe WJ. Disorders of the sebaceous glands. In:Textbook of Dermatology (Champion RH, Burton JL, Burns DA,Breathnach SM, eds). 6th edn. Vol.3. Oxford: Blackwell Science; 1998.p1942.

14. Kubba $R$, Bajaj AK, Thappa DM, Sharma $R$, Vedamurthy M, Dhar S. Acne in India: Guidelines for management - IAA Consensus Document: Epidemiology of acne. Indian J Dermatol Venereol Leprol 2009; 75(Suppl 1):p83

15. Thiboutot DM. Adapalene-Benzoyl peroxide, a fixed dose combination for the treatment of acne vulgaris: Results of a multicenter,randomized double-blind, controlled study. J Am Acad Dermatol.2007; 57(5): 791-9.

16. Stein-Gold L, Tan J, Werschler $W$ et al. A north american study of adapalene-benzoyl peroxide combination gel in the treatment of acne. Cutis.2009; 84(2): 110-6

17. Gollnick HPM, Draelos Z, Glenn MJ, et al. Adapalene-BPO Study Group, Adapalene-benzoyl peroxide, a unique fixed-dose combination topical gel for the treatment of acne vulgaris: a transatlantic, randomized, double-blind, controlled study in 1670 patients. Br J Dermatol.2009;161(5) : 1180-1189.

18. Andres $P$, Pernin $C$, Poncet $M$ et al. Adapalenebenzoyl peroxide once daily, fixed-dose combination gel for the treatment of acne vulgaris : a randomized, bilateral, (split-face), dose-assessment study of cutaneous tolerability in healthy participants. Cutis.2008;81(3): 278-84 